Acta Crystallographica Section E

Structure Reports

Online

ISSN 1600-5368

\section{(2E)-3-(Biphenyl-4-yl)-1-(4-chlorophenyl)- prop-2-en-1-one}

The title compound, $\mathrm{C}_{21} \mathrm{H}_{15} \mathrm{ClO}$, was prepared from biphenyl4-carbaldehyde and 4-chloroacetophenone. Single crystals Received 30 January 2007 Accepted 9 February 2007

\section{Andreas Fischer, ${ }^{\mathrm{a} *}$ H. S. Yathirajan, ${ }^{\text {b }}$ B. V. Ashalatha, ${ }^{\text {c }}$} B. Narayana ${ }^{c}$ and B. K. Sarojini ${ }^{d}$

anorganic Chemistry, School of Chemical Science and Engineering, Royal Institute of Technology (KTH), 10044 Stockholm, Sweden,

${ }^{\mathbf{b}}$ Department of Studies in Chemistry, University of Mysore, Manasagangotri, Mysore 570 006, India, ' Department of Chemistry, Mangalore University, Mangalagangotri 574 199, India, and ${ }^{\mathbf{d}}$ Department of Chemistry, P. A. College of Engineering, Nadupadavu, Mangalore 574 153, India

Correspondence e-mail: afischer@kth.se

\section{Key indicators}

Single-crystal X-ray study

$T=296 \mathrm{~K}$

Mean $\sigma(\mathrm{C}-\mathrm{C})=0.008 \AA$

$R$ factor $=0.067$

$w R$ factor $=0.160$

Data-to-parameter ratio $=13.3$

For details of how these key indicators were automatically derived from the article, see http://journals.iucr.org/e.
(C) 2007 International Union of Crystallography All rights reserved were obtained from acetone. The compound is isostructural with the corresponding $\mathrm{Br}$ compound. The molecule deviates significantly from planarity.

\section{Comment}

For an introduction, see Fischer et al. (2007a).

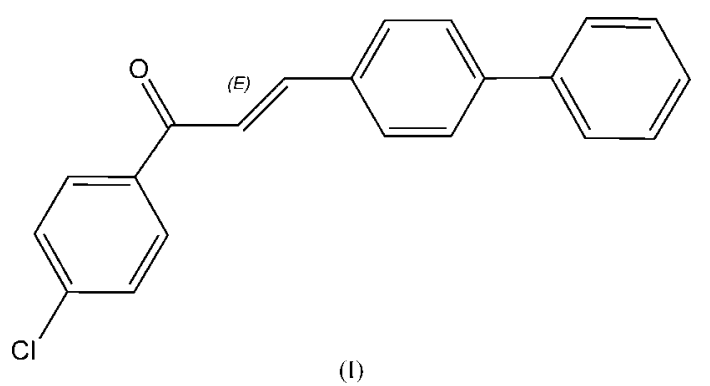

The title chalcone, (I), was prepared by treating 4-chloroacetophenone with biphenyl-4-carbaldehyde in the presence of $\mathrm{KOH}$.

Fig. 1 shows the molecular structure. The geometry of the molecule is unexceptional; its geometry deviates significantly from planarity [dihedral angles $4.42(16)^{\circ}$ within the biphenyl group and $48.85(16)^{\circ}$ between the $\mathrm{C} 10-\mathrm{C} 15$ ring and the chlorophenyl ring].

The compound is isostructural with the corresponding bromo compound (Fischer et al., 2007b).

\section{Experimental}

4-Chloroacetophenone (1.54 g, $0.01 \mathrm{~mol})$ in methanol $(20 \mathrm{ml})$ was mixed with biphenyl-4-carbaldehyde $(1.82 \mathrm{~g}, 0.01 \mathrm{~mol})$ and the

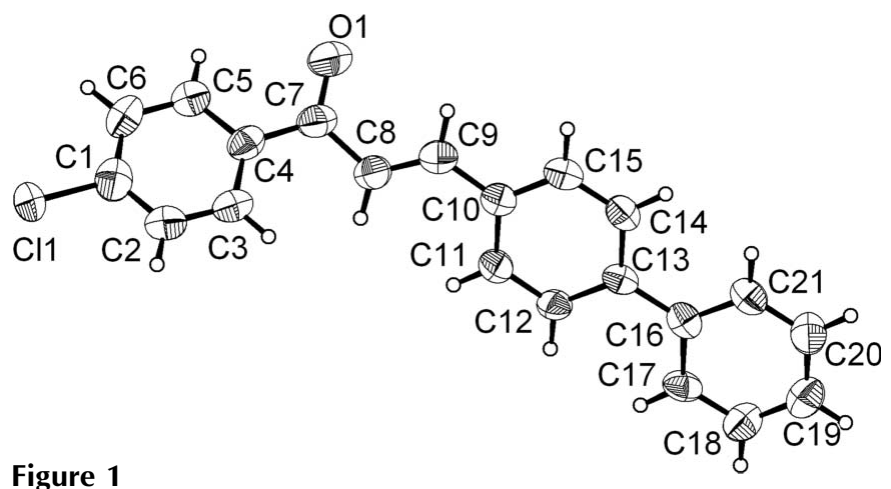

Figure 1

The molecular structure of the title compound. Displacement ellipsoids are drawn at the $50 \%$ probability level. 
mixture was treated with a $30 \%$ potassium hydroxide solution $(3 \mathrm{ml})$ at $278 \mathrm{~K}$. The reaction mixture was then brought to room temperature and stirred for $3 \mathrm{~h}$. The precipitated solid was filtered off, washed with water, dried and recrytallized from acetone (m.p. 439-441 K). Analysis (\%) for $\mathrm{C}_{21} \mathrm{H}_{15} \mathrm{ClO}$ found (calculated): $\mathrm{C} 76.83$ (76.94), $\mathrm{H}$ $4.86(4.92)$.

$\begin{array}{ll}\text { Crystal data } & \\ \mathrm{C}_{21} \mathrm{H}_{15} \mathrm{ClO} & V=1611.4(10) \AA^{3} \\ M_{r}=318.78 & Z=4 \\ \text { Monoclinic, } C c & \text { Mo } K \alpha \text { radiation } \\ a=36.723(14) \AA & \mu=0.24 \mathrm{~mm}^{-1} \\ b=7.303(3) \AA & T=296 \mathrm{~K} \\ c=6.0172(16) \AA & 0.58 \times 0.48 \times 0.04 \mathrm{~mm}\end{array}$

$\beta=93.06(3)^{\circ}$

\section{Data collection}

Bruker-Nonius KappaCCD diffractometer

Absorption correction: numerical (Herrendorf \& Bärnighausen, 1997)

$T_{\min }=0.716, T_{\max }=0.940$

\section{Refinement}

$R\left[F^{2}>2 \sigma\left(F^{2}\right)\right]=0.067$

$w R\left(F^{2}\right)=0.160$

$S=1.12$

2757 reflections

208 parameters

$\mathrm{H}$-atom parameters constrained

$$
\begin{aligned}
& \Delta \rho_{\max }=0.20 \text { e } \AA^{-3} \\
& \Delta \rho_{\min }=-0.16 \mathrm{e}^{-3} \\
& \text { Absolute structure: Flack (1983), } \\
& 1263 \text { Friedel pairs } \\
& \text { Flack parameter: } 0.02(15)
\end{aligned}
$$

2757 independent reflections 1756 reflections with $I>2 \sigma(I)$ $R_{\text {int }}=0.095$

$\mathrm{H}$ atoms were placed at calculated positions and refined as riding on the respective carrier atom, with $\mathrm{C}-\mathrm{H}=0.93 \AA$ and $U_{\text {iso }}(\mathrm{H})=$ $1.2 U_{\text {eq }}(\mathrm{C})$. The structure appears to exhibit turbostratic disorder, which could be detected in precession photographs that were simu- lated from the CCD data. The disorder was accounted for in the data processing with EVALCCD (Duisenberg et al., 2003).

Data collection: COLLECT (Nonius, 1999); cell refinement: $D I R A X / L S Q$ (Duisenberg, 1992); data reduction: EVALCCD (Duisenberg et al., 2003); program(s) used to solve structure: SIR97 (Altomare et al., 1997); program(s) used to refine structure: SHELXL97 (Sheldrick, 1997); molecular graphics: DIAMOND (Brandenburg, 2006); software used to prepare material for publication: publCIF (Westrip, 2007).

One of the authors (BKS) thanks AICTE, Government of India, for financial assistance through the Career Award for Young Teacher's Scheme, and BVA thanks Mangalore University for permission to carry out the research work. The Swedish Research Council (VR) is acknowledged for providing funding for the single-crystal diffractometer.

\section{References}

Altomare, A., Cascarano, C., Giacovazzo, C., Guagliardi, A., Moliterni, A. G. G., Burla, M. C., Polidori, G., Camalli, M. \& Spagna, R. (1997). SIR97. University of Bari, Italy.

Brandenburg, K. (2006). DIAMOND. Release 3.1d. Crystal Impact GbR, Bonn, Germany.

Duisenberg, A. J. M. (1992). J. Appl. Cryst. 25, 92-96.

Duisenberg, A. J. M., Kroon-Batenburg, L. M. J. \& Schreurs, A. M. M. (2003). J. Appl. Cryst. 36, 220-229.

Fischer, A., Yathirajan, H. S., Ashalatha, B. V., Narayana, B. \& Sarojini, B. K. (2007a). Acta Cryst. E63, o1349-o1350.

Fischer, A., Yathirajan, H. S., Ashalatha, B. V., Narayana, B. \& Sarojini, B. K. (2007b). Acta Cryst. E63, o1355-o1356.

Flack, H. D. (1983). Acta Cryst. A39, 876-881.

Herrendorf, W. \& Bärnighausen, H. (1997). HABITUS. University of Karlsruhe, Germany.

Nonius (1999). COLLECT. Nonius BV, Delft, The Netherlands.

Sheldrick, G. M. (1997). SHELXL97. University of Göttingen, Germany.

Westrip, S. P. (2007). publCIF. In preparation. 